\title{
Knowledge, Attitude and Practice of Physicians in the Treatment of Hypertension in North-Central Nigeria
}

\author{
Umar Gati Adamu1, Idogonsit Okon Ibok1, Aisha Abdullahi², Isaac Olajide Ogundele3 \\ George Alaba Okuku${ }^{4}$ \\ ${ }^{1}$ Department of Medicine, Federal Medical Centre, Bida, Nigeria \\ ${ }^{2}$ Department of Nursing Services, General Hospital, Minna, Nigeria \\ ${ }^{3}$ Department of Obstetrics and Gynaecology, Federal Medical Centre, Bida, Nigeria \\ ${ }^{4}$ Department of Hematology and Blood Transfusion, Federal Medical Centre, Bida, Nigeria \\ Email: ugadamu@yahoo.com
}

Received 31 March 2014; revised 2 May 2014; accepted 10 May 2014

Copyright (C) 2014 by authors and Scientific Research Publishing Inc.

This work is licensed under the Creative Commons Attribution International License (CC BY). http://creativecommons.org/licenses/by/4.0/

\section{Open Access}

\section{Abstract}

Background and Objectives: Hypertension is a global health hazard and most cases are first attended to by the physicians. Achieving a control will depend on the knowledge, attitude and practice of the physicians. We therefore determined the knowledge, attitude and practices of physicians on the detection and treatment of arterial hypertension in north-central Nigeria. Design and Methods: A cross-sectional study of 100 of the 250 physicians attending a continuing medical education lecture series in Bida was conducted using a pre-validated self administered questionnaire. Results: The mean age of the physicians was $41.05 \pm 8.71$ years and $59(73.8 \%)$ were males. Fortyone (51.2\%) of them have practiced for more than 10 years. Arterial hypertension was considered an important health problem by $\mathbf{9 3 . 8 \%}$ of the physicians, $30 \%$ of them believed that it should not be referred to a specialist. Majority of the physicians request for urinalysis (96.2\%), electrocardiogram $(\mathbf{9 5 . 0} \%)$, fasting blood glucose $(\mathbf{8 8 . 8 \%})$, blood urea nitrogen $(\mathbf{9 8 . 8} \%)$ and fasting lipid profile $(\mathbf{9 7 . 5 \% )}$ to either assess target organ damage or associated co-morbid conditions. Fifty-seven (71.2\%) of the physicians prescribe diuretics as the initial drug. However, the knowledge of the other drugs on initiation of therapy of mild uncomplicated hypertension was poor. The sources of information on arterial hypertension by physicians were scientific programs $(\mathbf{7 3 . 8 \%})$, drug companies $(38.8 \%)$ and journals in $\mathbf{1 1 . 3 \%}$. Conclusion: The knowledge, attitude and practice of physicians in the detection and management of hypertension were modest. Educative programs like continuing medical education, seminars, and conferences on cardiovascular disorders are advised to be organized regularly to strengthen these and update the physicians.

\section{Keywords}

Arterial Hypertension, Physicians, Continuing Medical Education, North-Central Nigeria 


\section{Introduction}

Arterial hypertension is a global health hazard that is frequently encountered in clinical practice. The prevalence of arterial hypertension in Nigeria is on the rise, with age adjusted prevalence of $9.3-14.5 \%$ [1]-[3] during the 90 's to between $20 \%$ - 25\% according to recent studies [4] [5]. This translates to about 37 million Nigerians with arterial hypertension.

There is still uncertainty about the pathogenesis of arterial hypertension. However, derangement of physiological mechanisms involved in the maintenance of normal blood pressure, and an underlying renal or adrenal disease may play a part in its development [6]. Most patients with arterial hypertension are asymptomatic except when there are complications. It is thus imperative for physicians since most of the clinical features and laboratory findings are referable to involvement of the target organs: heart, brain, kidneys, eyes, and peripheral arteries [7].

Continuing medical education is a specific form of continuing education that helps those in the medical field maintain competence and learn about new and developing areas of their field. Physicians attend at regular intervals to acquire credit units to maintain their licenses by the professional regulating bodies.

Previous studies have shown that dissemination and implementation of guidelines on arterial hypertension by the physicians on the care of patients are lacking [6]. This knowledge gap will result in the provision of ineffective services. Hence, achieving a control and adopting preventing measures to this highly prevalent disease should be a collective effort of all cadres of physicians. Since individuals with hypertension are likely to be seen first by physicians at the community level, ascertaining their knowledge, attitude and practice is fundamental for effective diagnosis, evaluation and treatment [7]-[10].

The aim of this study was to determine the knowledge, attitude and practices of physicians on arterial hypertension in relation to detection, investigation and treatment.

\section{Materials and Methods}

A cross-sectional survey of one hundred of the 250 physicians that attended the continuing medical education series in Bida in September, 2011 were randomly recruited for this study. The questionnaire was pre-tested on 10 randomly selected residents' doctors in the hospital to ensure validity and interpretation of responses. It consisted of questions on knowledge, attitude, and practice of physicians on the diagnosis, evaluation and treatment of hypertension. Items in the questionnaire included demographic data, place of practice, and year of graduation. Responses to items for the three areas of knowledge, attitude and practice were yes, no, or don't know. The level of knowledge, attitude and practice mean percentage score was considered poor if it is less than 50\%, fair (modest), from $50 \%$ to $75 \%$, and good if more than $75 \%$. Medical practitioners with specialist training were excluded. Ethical approval was granted by Ethical Committee of Federal Medical Centre, Bida.

\section{Statistical Analysis}

The statistical package for social sciences SPSS, version 16.0 (SPSS Inc., Chicago, Illinois, USA) was used for statistical analysis. Categorical variables were expressed as proportions and percentages while continuous variables were expressed by their mean and standard deviation. For all comparisons, a p value of less than 0.05 was considered significant.

\section{Results}

\subsection{General Characteristics of Physicians}

Out of the one hundred questionnaires administered, 80 (80\%) were returned completed and qualified for assessment. The responding physicians age ranged between 27 to 68 years with a mean of $41.05 \pm 8.71$ years. There were more males than females $(73.75 \%$ versus $26.25 \%$, p $=0.000)$. The years of clinical experience ranged from one year to 40 years, with a median duration of 11 years. Twenty-one (26.3\%) of the physicians have practiced for between 1 to 5 years, 17 (21.2\%) have their years of experience ranging from 6 to 10 years while those with more than 10 years represented $51.2 \%$. The age of physicians correlated positively with the years of clinical practice $(\mathrm{p}=0.000)$ (Table 1$)$. 
Table 1. Demographic characteristics of the physicians.

\begin{tabular}{cc}
\hline Age (years) & $41.05 \pm 8.71$ \\
Gender (male/female) & $74 / 26$ \\
Duration of practice (years) & $13.09 \pm 9.05$ \\
Place of clinical practice & $\mathrm{n}(\%)$ \\
Government hospital & $57(71.3)$ \\
Private & $17(21.2)$ \\
Ministry & $2(2.5)$ \\
Others & $4(5.0)$ \\
\hline
\end{tabular}

Data are expressed as mean \pm standard deviation or as percentage values.

\subsection{Knowledge of Physicians on Investigation of Arterial Hypertension}

Most of the physicians (93.8\%) believed that arterial hypertension is a global health problem. In making a diagnosis of arterial hypertension, $10 \%, 35 \%$ and $55 \%$ of the physicians believed that one, two and three visits were enough respectively. Only $30 \%$ of them referred their patients with arterial hypertension with complication to specialist. A good blood pressure control was considered to be 120/75 mmHg, 130/80 $\mathrm{mmHg}$ and 140/90 $\mathrm{mmHg}$ by $45 \%, 30 \%$ and $25 \%$ of the physicians respectively. Fifty-one of them $(63 \%)$ indulged in self treatment of hypertension. Forty-one (51.2\%) of the respondents agreed that hypertension is stress related and 61 (76.2\%) do not believe in herbal treatment of hypertension. Forty-one (51.2\%) of the respondents agreed that hypertension is stress related and $61(76.2 \%)$ do not believe in herbal treatment of hypertension. Forty-six (57.5\%) of the physicians send their patients for laboratory investigations to determine target organ damage, but more (81.3\%) to assess for associated co-morbid condition (Table 2). Although $73.8 \%$ of the physicians believed that education programs such as continuing medical education, seminars and conferences were a better way to gather information. Other sources include drug companies, advertisements and journals.

\subsection{Attitude and Practice of Physicians on Management of Hypertension}

Table 3 shows the attitude and practices of physicians in the management of arterial hypertension. A total of 75 physicians (93.7\%) agreed that hypertension is an important health hazard and stress is an important causative factor. Despite the high patronage of herbal remedy that is evident in our society, only $12.5 \%$ prescribed it for their patients. Regarding the treatment of arterial hypertension, $36.3 \%$ and $71.2 \%$ of the physicians reported initiating therapy with angiotensin converting enzyme inhibitors and diuretics respectively. Calcium channel blockers are rarely (22.5\%) the first line drug prescribed by the physicians. The level of knowledge in the present study with regards to patients with refractory hypertension is such that 31 (38.8\%) of them believed in adjusting the dose of the drugs while 36 (45.0\%) of them disagreed.

\section{Discussion}

The main findings from this study were that majority of the physicians agreed that arterial hypertension is an important health problem. Secondly, a substantial number of them refer their patients for various laboratory investigations to determine target organ damage or associated co-morbidities. However, their knowledge of current antihypertensive drugs therapy was poor.

The finding of our study is consistent with a study by Zibaeenezhad et al. [11] conducted in the Fars Province of southern Iran, where the knowledge, attitude and practice of general practitioners were evaluated in relation to hypertension as risk factors for heart diseases. The report demonstrated that almost all the primary care physicians believed arterial hypertension was an important health problem and needed to know more about it. In another study in Saudi Arabia by Ai-Dharrab et al. [12], about $80 \%$ of their participants also believed that arterial hypertension is an important health hazard. Arterial hypertension is viewed a priority problem by $62.5 \%$ of Egyptian physicians [13]. In this same study, the level of knowledge varied with regard to definition of hypertension (61.3\%) and treatment of hypertension was fair in 59.8\% although, only $19 \%$ had guidelines on hypertension.

Our study demonstrated that about $86.2 \%$ of physicians agreed that there was need for hypertensive patients to have laboratory evaluation, but eventually only $57.8 \%$ actually send their patients to ascertain target organ 
Table 2. Knowledge and practice of physicians about investigation of hypertension.

\begin{tabular}{|c|c|c|c|}
\hline Parameters & Agree n (\%) & Disagree n (\%) & Don’t known (\%) \\
\hline Need for tests & $69(86.2)$ & $7(8.8)$ & $4(5.0)$ \\
\hline Evaluation for the presence or absence of target organ damage & $46(57.5)$ & $28(35.0)$ & $6(7.5)$ \\
\hline Evaluation for other co-morbid risk factors & $65(81.3)$ & $0(0)$ & 15 (18.7) \\
\hline Type of tests: urinalysis & 77 (96.1) & $2(2.5)$ & $1(1.2)$ \\
\hline Blood glucose estimation & $71(88.8)$ & $4(5.0)$ & $5(6.2)$ \\
\hline Kidney function test & 79 (98.8) & $0(0)$ & $1(1.2)$ \\
\hline Electrocardiography & $76(95.0)$ & $1(1.2)$ & $3(3.8)$ \\
\hline Fasting lipid profile & $78(97.5)$ & $0(0)$ & $2(2.5)$ \\
\hline Referral to specialist & $24(30.0)$ & $52(65.0)$ & $4(5)$ \\
\hline
\end{tabular}

Data are expressed as percentage values.

Table 3. Knowledge and attitudes of physicians about hypertension therapy.

\begin{tabular}{|c|c|c|c|}
\hline Parameters & Agree n (\%) & Disagree n (\%) & Don’t known (\%) \\
\hline Hypertension is an important health hazard & 75 (93.7) & $2(2.5)$ & $3(3.8)$ \\
\hline Stress is a cause of hypertension & $41(51.2)$ & $31(38.8)$ & $8(10.0)$ \\
\hline Non pharmacological treatment of hypertension & $52(65.0)$ & $28(31.3)$ & $3(3.7)$ \\
\hline Herbal treatment for hypertension & $10(12.5)$ & $61(76.2)$ & $9(11.3)$ \\
\hline Central acting drugs as first line of therapy & $18(22.5)$ & $43(53.7)$ & $19(23.8)$ \\
\hline Diuretics as first line drug & $57(71.2)$ & $17(21.3)$ & $6(7.5)$ \\
\hline Calcium channel blockers as first line drug & $67(46.2)$ & $33(41.3)$ & $10(10.5)$ \\
\hline Angiotensin converting enzyme inhibitors as first line & $29(36.3)$ & $38(47.5)$ & $13(16.2)$ \\
\hline Alteration of dug should be the next line in case of treatment failure & $31(38.8)$ & $36(45.0)$ & $13(16.2)$ \\
\hline Discontinuation of all drugs in case of treatment failure & $9(11.3)$ & $64(80.0)$ & $7(8.7)$ \\
\hline
\end{tabular}

Data are expressed as percentage values.

damage and $81.3 \%$ to rule out associated co-morbid medical conditions. This modest attitude to screening of patients was also established in a study by Al-Khashman [14] in screening people for hypertension in Riyadh, Kingdom of Saudi Arabia where 56\% of the primary care physicians routinely screen patients that are more than 35 years of age. In a large study by Hagemeister et al. [15] of 11,547 German physicians on the impact of physicians' compliance on hypertension guidelines, adequate guideline awareness was only found in $23.7 \%$ of the total study population, specifically $37.1 \%$ of the Cardiologists complied, $25.6 \%$ of internists and $18.8 \%$ of the general practitioners. The duration of private practice significantly influenced the awareness of and less so by regional and municipal factors. In our study, the duration of clinical practice had insignificant effect on responses by the physicians. This might not be unconnected to the fact that, most of these older physicians have undergone several of these continuing medical education courses.

About $30 \%$ of physicians reported that they would refer patients with arterial hypertension for specialist care after diagnosis. This finding from our study is consistent with the report by Abdolfotouh et al. [13] in primary healthcare physicians in Egypt, where only $43.5 \%$ of them refer patients for expert care. This practice might be due to the fact that most physicians either practice in private or general hospitals with very low standards of care and where most don't attend update or refresher courses. Although, management of these patients starts with the physicians, they should realize that the cornerstone of management of hypertensive cases is accurate diagnosis and referral of cases without delay to the specialist [16].

In our study, scientific programs are the commonest way to gather information concerning hypertension management (73.8\%) followed by drug companies (38.8\%) and journals (11.3\%) while internet and textbooks accounted for $6.4 \%$ and $7.1 \%$ respectively. This is related to the finding by Zibaeenezhad et al. [11] which demonstrated that $70 \%$ of their physicians received their information from previous educational courses and scientific meetings and only $30 \%$ from articles and guidelines.

In the present study, most of the physicians favour the use of diuretics $71.2 \%$ in the treatment of mild uncomplicated hypertension. Few of them chose calcium channel blockers, angiotensin converting enzyme inhibitors, 
and centrally acting drugs (46.2\%, 36.2\% and 22.5\%) respectively. This is not consistent with the study of Huse et al. [17], which demonstrated that only $23 \%$ used diuretics and beta-blockers as their initial drug in accordance with the guidelines and that Cardiologists in particular were more likely than internists or general/family physicians to choose other drug classes, such as angiotensin-converting enzyme Inhibitors or calcium-channel blockers. The high rate of use of diuretics in this study might be due to the fact that hypertension in blacks is said to be volume dependant [18].

The present study has a number of limitations. First, the sample size for the study was small and therefore making the results less generalizable, hence studies with larger sample size are advised. Second, although questionnaire used was pre-validated, the respondents could have been biased with their answers. Finally, the exclusion of physicians with specialist training who would have been used for comparison is another factor.

\section{Conclusions}

In conclusion, this study demonstrated that the knowledge, attitude and practice of physicians in North-central Nigeria on the detection, investigation and treatment of arterial hypertension are modest and scientific programs like continuing medical education among others are important media of acquiring information.

It is hoped that the study will add to the limited knowledge and broaden the understanding of hypertension treatment by physicians in Nigeria and could therefore be extremely useful in planning further continuing medical education.

\section{References}

[1] Akinkugbe, O.O. (1997) Non-Communicable Diseases in Nigeria-Final Report of a National Survey. Federal Ministry of Health-National Expert Committee on Non-Communicable Diseases, Lagos, 1-12.

[2] (2003) The Seventh Report of the Joint National Committee on Prevention, Detection, Evaluation, and Treatment of High Blood Pressure (JNC 7). JAMA, 289, 2560-2572. http://dx.doi.org/10.1001/jama.289.19.2560

[3] Cooper, R., Rotimi, C., Ataman, S., McGee, D., Osotimehin, B., Kadiri, S., Muna, W., Kingue, S., Fraser, H., Forrester, T., Bennett, F. and Wilks, R. (1997) The Prevalence of Hypertension in Seven Populations of West African Origin. American Journal of Public Health, 87, 160-168. http://dx.doi.org/10.2105/AJPH.87.2.160

[4] Ulasi, I.I., Ijoma, C.K. and Onodugo, O.D. (2010) A Community Based Study of Hypertension and Cardiometabolic Syndrome in Semi-Urban and Rural Communities in Nigeria. BMC Health Services Research, 10, 71. http://dx.doi.org/10.1186/1472-6963-10-71

[5] Ogah, O.S., Madukwe, O.O., Chukwuonye, I.I., Onyeonoro, U.U., Ukaegbu, A.U., Akhimien, M.O., Onwubere, B.J.C. and Okpechi, I.G. (2013) Prevalence and Determinants of Hypertension in Abia State Nigeria: Results from the Abia State Non-Communicable Diseases and Cardiovascular Risk Factors Survey. Ethnicity \& Disease, 23, 161-167.

[6] Barker, D.J.P., Osmond, C., Golding, J., Kuh, D. and Wadsworth, M.E.J. (1989) Growth in Utero, Blood Pressure in Childhood and Adult Life and Mortality from Cardiovascular Disease. BMJ, 298, 561-567. http://dx.doi.org/10.1136/bmj.298.6673.564

[7] Chobanian, A.V., Bakris, G.L., Black, H.R., et al. (2003) Joint National Committee on Prevention, Detection, Evaluation, and Treatment of High Blood Pressure; National Heart, Lung, and Blood Institute; National High Blood Pressure Education Program Coordinating Committee: Seventh Report of the Joint National Committee on Prevention, Detection, Evaluation, and Treatment of High Blood Pressure. Hypertension, 42, 1206-1252. http://dx.doi.org/10.1161/01.HYP.0000107251.49515.c2

[8] Cabana, M.D., Rand, C.S., Neil, R.P., Wu, A.V., Wilson, M.H., Abboud, P.A. and Rubin, H.R. (1999) Why Don’t Physicians Follow Clinical Practice Guidelines? JAMA, 282, 1458-1465. http://dx.doi.org/10.1001/jama.282.15.1458

[9] Mead, M. (1988) Hypertension the GP Perspective. Update, 2, 875-876.

[10] Guyther, J.R. and Kochar, M.S. (1981) The Family Physician’s Role in Detection and Control of Hypertension. Family \& Community Health, 4, 21-27. http://dx.doi.org/10.1097/00003727-198105000-00006

[11] Zibaeenezhad, M.J., Babaee, H. and Vakili, S.H. (2007) Knowledge, Attitude and Practice of General Physicians in Treatment and Complications of Hypertension in Fars Province, Southern Iran. Iranian Red Crescent Medical Journal, 9, 4-8.

[12] Ai-Dharrab, S.A., Mangoud, A.M. and Mohsen, M.F. (1996) Knowledge, Attitude and Practice (KAP) of Primary Health Care Physicians and Nurses towards Hypertension: A Study from Dammam, Saudi Arabia. Journal of Family and Community Medicine, 3, 57-63.

[13] Abolfotouh, M.A., Soliman, L.A., Abolfotouh, S.M. and Raafat, M. (2011) Knowledge and Practice of PHC Physicians 
toward the Detection and Management of Hypertension and Other CVD Risk Factors in Egypt. International Journal of Hypertension, 2011, Article ID: 983869. http://dx.doi.org/10.4061/2011/983869

[14] Al-Khashman, A.S. (2001) Screening for Hypertension. Assessing the Knowledge, Attitudes and Practice of Primary Health Care Physicians in Riyadh, Saudi Arabia. Saudi Medical Journal, 22, 1096-1100.

[15] Hagemeister, J., Schneider, J., Schneider, C.A., Barabas, S., Schadt, R., Wassmer, G., Mager, G., Pfaff, H. and Hoepp, H.W. (2001) Hypertension Guidelines and Their Limitations-The Impact of Physicians' Compliance as Evaluated by Guideline Awareness. Journal of Hypertension, 19, 2079-2086. http://dx.doi.org/10.1097/00004872-200111000-00020

[16] Akinkugbe, A., Gant, N.F., Kincaid-Smith, P., Peyser, M.R., Raman, L. and Sinnathuray, T.A. (1987) The Hypertensive Disorders of Pregnancy. WHO Study Group, Geneva, Report No: 758.

[17] Huse, D.M., Roht, L.H., Alpert, J.S. and Hartz, S.C. (2001) Physicians’ Knowledge, Attitudes, and Practice of Pharmacologic Treatment of Hypertension. Annals of Pharmacotherapy, 35, 1173-1179. http://dx.doi.org/10.1345/aph.10204

[18] Oyewo, E.A., Ajayi, A.A. and Ladipo, G.O.A. (1989) A Therapeutic Audit in the Management of Hypertension in Nigerians. East African Medical Journal, 66, 458-467. 